\title{
Fetal Growth Restriction Has Long-Term Effects on Postnatal Lung Structure in Sheep
}

\author{
GERT S. MARITZ, MEGAN L. COCK, SAMANTHA LOUEY, KEIJI SUZUKI, AND \\ RICHARD HARDING \\ Department of Physiological Sciences, University of the Western Cape, 7535 Bellville, South Africa \\ [G.S.M.], and Department of Physiology, Monash University, Melbourne 3800, Australia [M.L.C., S.L., \\ K.S., R.H.]
}

\begin{abstract}
We have previously shown that fetal growth restriction (FGR) during late gestation in sheep affects lung development in the near-term fetus and at $8 \mathrm{wk}$ after birth. In the present study, our aim was to determine the effects of FGR on the structure of the lungs at 2 y after birth; our hypothesis was that changes observed at 8 wk after birth would persist until maturity. FGR was induced in sheep by umbilicoplacental embolization, which was maintained from $120 \mathrm{~d}$ until delivery at term (approximately $147 \mathrm{~d}$ ); birth weights of FGR lambs were $41 \%$ lower than in controls. At 2 y after birth, body and lung weights were not different, but there were $28 \%$ fewer alveoli and alveoli were significantly larger than in controls; hence there was a $10 \%$ reduction in the internal surface area relative to lung volume in FGR sheep compared with controls. The lungs of FGR sheep, compared with controls, had thicker interalveolar septa as a result of increased extracellular matrix deposition; the alveolar blood-air barrier was also thicker, largely because of an $82 \%$ increase in basement membrane thickness. These changes are qualitatively similar to those observed at $8 \mathrm{wk}$. Our data show that structural alterations in the lungs induced by FGR that were apparent at $8 \mathrm{wk}$ were still evident at 2 y after birth, indicating that FGR may result in permanent changes in the structure of the lungs of the offspring
\end{abstract}

\section{ABSTRACT}

and may affect respiratory health and lung aging later in life.

(Pediatr Res 55: 287-295, 2004)
BW, body weight
Abbreviations
ECM, extracellular matrix
FGR, fetal growth restriction
GA, gestational age
Lm, mean linear intercept
$\mathbf{N}_{\mathbf{A}}$, number of alveoli
$\mathrm{PaCO}_{2}$, arterial partial pressure of carbon dioxide
$\mathrm{PaO}_{2}$, arterial partial pressure of oxygen
RER, rough endoplasmic reticulum
$\mathbf{S}_{\mathbf{A}}$, internal surface area
$\mathbf{S}_{\mathbf{V}}$. surface density of the lung
TEM, transmission electron microscopy
$\mathbf{T}_{\mathbf{h B A B}}$, harmonic mean thickness of blood-air barrier
Tw, septal thickness
UPE, umbilicoplacental embolization
Valv, alveolar volume
$\mathbf{V}_{\mathbf{A}}$, percent airspace of the lungs
$\mathbf{V}_{\mathbf{L}}$, right lung volume

Low birth weight as a result of FGR has been associated with an increased risk of morbidity and mortality during infancy $(1,2)$. It is likely that altered lung development may be a contributing factor as it has been shown that the risk of respiratory illness and the requirement for ventilatory support is increased in FGR infants $(3,4)$. Respiratory impairments may persist into later life because low birth weight children who were growth-restricted in utero $(5,6)$, as well as adults having low birth weights $(7,8)$, have evidence of impaired lung function. At present, however, the structural basis for a rela-

Received December 23, 2002; accepted September 12, 2003.

Correspondence: R. Harding, Ph.D., Department of Physiology, Monash University, VIC 3800, Australia; e-mail: richard.harding@med.monash.edu.au

Funded by the FRD and MRC of South Africa and the National Health and Medical Research Council of Australia.

DOI: 10.1203/01.PDR.0000106314.99930.65 tionship between FGR and later pulmonary dysfunction is poorly understood.

The sheep is a suitable animal model in which to study the effects of FGR on lung development; it is a long-gestation species in which alveolar formation begins before birth (9), as in the human (10), and which reaches sexual maturity 6 mo after birth. Recently we found, in developing sheep, that fundamental aspects of respiratory function were impaired after FGR; FGR lambs were hypoxemic and hypercapnic soon after birth and had reduced pulmonary diffusing capacity and lung compliance up to $8 \mathrm{wk}$ (11). In addition to these functional alterations, we found that FGR induced structural changes in lung parenchyma that were evident in the near-term fetus and became more pronounced at $8 \mathrm{wk}$ after birth (12). In particular, the blood-air barrier and structure of interalveolar septa were affected after FGR. It is possible that structural 
changes may compromise the diffusion capacity of the lungs and other aspects of lung function of the offspring; hence we considered it necessary to establish whether these changes are permanent.

To determine whether alterations in lung structure observed in FGR animals at $8 \mathrm{wk}$ of age persist into maturity we have performed a structural analysis of lung tissue from postnatal sheep at approximately $2 \mathrm{y}$ after birth. We induced FGR by UPE as it replicates key features of human FGR $(13,14)$ and the metabolic, cardiovascular, and endocrine effects of UPE have been defined (15-17). Our hypothesis was that changes in lung development induced by placental insufficiency and FGR during late gestation, coinciding with the saccular and alveolar phases of lung development, persist into adulthood. In addition, we measured pulmonary elastin content, as changes in elastin could affect mechanical properties of the lungs. We found that changes that were evident in FGR animals at $8 \mathrm{wk}$ after birth (12) were even more evident at $2 \mathrm{y}$ of age.

\section{METHODS}

Surgical procedures. Sixteen pregnant ewes carrying 19 fetuses (nine with single fetuses, seven with twins) underwent aseptic surgery at $116 \pm 1$ (SEM) days after mating (term is approximately $147 \mathrm{~d})$, as previously described $(17,18)$. Anesthesia was induced with sodium thiopental $(1 \mathrm{~g}$ i.v. $)$ and maintained by halothane $\left(1.5-2.0 \%\right.$ in $\left.\mathrm{O}_{2}\right)$. The fetal hindquarters were exposed, and a catheter for both blood sampling and the injection of microspheres for inducing UPE was implanted into the fetal descending aorta via a femoral artery such that its tip lay between the level of the renal arteries and common umbilical artery (17). A catheter was inserted into the amniotic sac so that amniotic fluid pressure could be monitored; in addition electromyographic electrodes were sutured to the uterus. Procaine penicillin $(500 \mathrm{mg}$ ) and dihydro-streptomycin $(500 \mathrm{mg})$ were injected into all fetuses (i.m.) before uterine closure. After exteriorization of catheters and closure of surgical sites, sheep were housed in individual cages. In addition to the sheep described above, we used four normal (control) sheep that had not undergone surgery to provide a gender balance between FGR and control groups. Details of animals in the two groups are given in Table 1. This study was approved by the relevant institutional ethics committees.

Induction of FGR. FGR was induced in 12 fetuses (seven males, five females) by UPE from $120 \mathrm{~d}$ of gestational age (GA) until the onset of labor. Insoluble microspheres (40-70 $\mu \mathrm{m}$ in diameter) were injected daily into the fetal femoral artery catheter, sufficient to reduce fetal $\mathrm{PaO}_{2}$ by approximately $8 \mathrm{~mm} \mathrm{Hg}$ below pretreatment $\mathrm{PaO}_{2}(17,18)$. Fetuses forming the control group ( $n=11$; four males, seven females) were

Table 1. Numbers of maternal ewes and their offspring used in this study

\begin{tabular}{lccc}
\hline & Maternal ewes & $\begin{array}{c}\text { Offspring } \\
\text { (male/female) }\end{array}$ & $\begin{array}{c}\text { Offspring } \\
(\text { single/twin)* }\end{array}$ \\
\hline Control & 11 & $4 / 7$ & $11 / 0$ \\
FGR & 9 & $7 / 5$ & $2 / 10$ \\
\hline
\end{tabular}

* Within a twin pregnancy, one or both lambs were used. subjected to daily injections of saline or were not operated on (three males, one female). In all fetuses, we made daily measurements of arterial oxygen saturation, $\mathrm{PaO}_{2}, \mathrm{PaCO}_{2}, \mathrm{pH}$, and glucose and lactate concentrations.

Once labor commenced, ewes were closely monitored until lambs were born, delivery being assisted if necessary. All lambs were born spontaneously per vaginum at term, except one FGR animal in which delivery was induced owing to deteriorating fetal condition. Immediately after birth, lambs were dried and weighed, and the catheters were reconnected to stopcocks and secured beneath elasticized netting. At regular intervals up to $12 \mathrm{wk}$ after birth, the animals were weighed, and arterial gas tensions and $\mathrm{pH}$ measured. At $12 \mathrm{wk}$, catheters were removed, and the animals were placed in a pasture; after this, blood samples were taken less frequently using temporary arterial catheters.

At $841 \pm 21 \mathrm{~d}$ after birth (FGR, $810 \pm 22.7 \mathrm{~d}$; controls, 874 $\pm 35.2 \mathrm{~d} ; p>0.05$ ), animals were humanely killed with an overdose of sodium pentobarbitone (i.v.). Static lung compliance was measured, with the sheep in a supine position, after intubating the trachea and exposing the lungs via a ventral thoracotomy. While recording airway pressure, the lungs were increasingly inflated at $500-\mathrm{mL}$ increments to reach a maximum volume of $3000 \mathrm{~mL}$; the lungs were then progressively deflated. The inflation-deflation procedure was performed in triplicate. Lung compliance was calculated from the slope of the deflation limb of the pressure-volume curve between 2.0 and $0.5 \mathrm{~L}$; this range included the fixed $\mathrm{V}_{\mathrm{L}}$ (described below). The deflation limb was studied as it reflects mainly the tissue elastic components and is less influenced by surfactant (19).

Lung tissue analysis. Pulmonary DNA and soluble protein concentrations in lung tissue were determined using established fluorometric DNA and colorimetric protein assays, respectively (11). Pulmonary elastin content was quantified using a modification of an established method (20). Briefly, lung tissue was microdissected to remove larger airways and blood vessels, homogenized in $0.15 \mathrm{M} \mathrm{NaCl}$, then centrifuged; the pellet was resuspended in $5 \mathrm{M}$ guanidine $\mathrm{HCl}$ and incubated for $24 \mathrm{~h}$ at $25^{\circ} \mathrm{C}$ followed by centrifugation and a second incubation in $5 \mathrm{M}$ guanidine $\mathrm{HCl}$ for $24 \mathrm{~h}$ to remove soluble proteins. The tissue extract was then washed, resuspended in distilled water, and autoclaved at $120^{\circ} \mathrm{C}$ to solubilize and remove collagen. The pellet was washed further in distilled water, and the remaining tissue extract, considered to be elastin according to amino acid analysis (20), was made soluble by elastase. The resulting peptides were quantified using a standard protein assay.

Histologic preparation of lung tissue. Body and organ weights were recorded, and the lungs were removed. The left bronchus was ligated, and fixative (4\% paraformaldehyde and $0.2 \%$ glutaraldehyde in $0.1 \mathrm{M}$ phosphate buffer, $\mathrm{pH} 7.4$ ) was infused into the right lung via the trachea at $20 \mathrm{~cm} \mathrm{H}_{2} \mathrm{O}$; the left lung was removed for biochemical analysis. After fixation, the trachea was ligated, and the right lung was placed in a container of fresh fixative at $4{ }^{\circ} \mathrm{C}$ for $24 \mathrm{~h}$. The volume of the right lung fixed at $20 \mathrm{~cm} \mathrm{H}_{2} \mathrm{O}\left(\mathrm{V}_{\mathrm{L}}\right)$ was determined by volume displacement (21), after which tissue samples were taken from the upper, middle, and lower lobes. Lung volumes were deter- 
mined before and after the 24-h fixation period to detect shrinkage. Because of minimal shrinkage $(<2 \%)$, data were not corrected for shrinkage. After the lung volumes were determined, sections were embedded in paraffin wax, and $4-\mu \mathrm{m}$ sections were cut and stained with hematoxylin and eosin. The linear shrinkage of tissue blocks was determined before and after processing with the use of a calibrated eyepiece micrometer. Linear shrinkage was $3.2 \pm 0.3 \%$. Tissue blocks were trimmed at right angles to enable accurate measurements of shrinkage. For light microscopy, tissue samples were taken from each lobe and cut into $1 \times 1 \times 0.5-\mathrm{cm}$ portions that were embedded in paraffin wax. For TEM and scanning electron microscopy, three samples from each lobe were cut into cubes (approximately $1 \mathrm{~mm}^{3}$ and $8 \mathrm{~mm}^{3}$, respectively). The cubes for TEM were washed in $0.1 \mathrm{M}$ cacodylate buffer, incubated in $2.0 \% \mathrm{OsO}_{4}$ for $2 \mathrm{~h}$, washed again in cacodylate buffer, and then incubated in $1 \%$ uranyl acetate for $2 \mathrm{~h}$. They were again washed in maleate buffer, and progressively dehydrated in increasing ethanol concentrations before being embedded in Spurr's resin. Three tissue sections from two randomly selected blocks from each of the lobes were used for morphometric and TEM analysis.

Scanning electron microscopy was used to examine the surface morphology of the alveoli in four sheep of each group. After fixation, tissue samples were dehydrated and dried; they were then coated with gold using a sputter coater (22). We examined three to four fields in each of three blocks taken from each animal.

For morphometric analysis by light microscopy, sections (5 $\mu \mathrm{m})$ were prepared from paraffin-embedded samples and stained with hematoxylin and eosin. For TEM, ultrathin sections $(70-90 \mathrm{~nm})$ were prepared using an ultramicrotome. Sections were mounted on copper grids and stained with uranyl acetate, rinsed with distilled water, and then stained in lead citrate.

Morphometric analysis. All measurements were performed blind by the same observer (G.S.M.). Using the 5- $\mu \mathrm{m}$ paraffin sections, the Lm, or average distance between alveolar walls, $\mathrm{Tw}$, and the air and tissue volume densities were determined; Tw included the blood-air barrier and the parenchyma of the alveolar walls. An alveolus was defined as an airspace either completely enclosed by respiratory epithelium or having a smooth rounded contour for more than one third of a projected circle, with the remaining boundary formed by an imaginary line between the distal ends of secondary septa. For all of the above variables, at least 15 nonoverlapping fields from each section were analyzed. The total $\mathrm{N}_{\mathrm{A}}$ was determined using the following equation: $\mathrm{N}_{\mathrm{A}}=\mathrm{V}_{\mathrm{L}} \times \mathrm{V}_{\mathrm{A}} / \mathrm{Valv}$ (23), where $\mathrm{V}_{\mathrm{A}}$ is the percentage airspace of the lung and Valv is the mean alveolar volume, computed as $\mathrm{Lm} \times \pi / 3$ (24). The airspace wall surface area per unit volume $(\mathrm{Sv}=2 / \mathrm{Lm})$ was determined as described previously (25) and is expressed as square millimeter per cubic millimeter. The $\mathrm{S}_{\mathrm{A}}$ was calculated by using the formula $4 \times \mathrm{V}_{\mathrm{L}} / \mathrm{Lm}$ (26). To avoid sampling bias, the lungs were sectioned at different sectioning planes (27). Analyses were performed at $\times 400$ magnification.

Using TEM (28), we measured the $\mathrm{T}_{\mathrm{hBAB}}$ (the distance that respiratory gases must travel), which was defined as the cap- illary endothelial cell, the type 1 epithelial cell, and the basement membranes between the endothelial and epithelial cells; we also measured the harmonic mean thickness of the components of the blood-air barrier (29).

Statistical analysis. Data on blood composition were analyzed by ANOVA (two-way, repeated measures, and $t$ test), and data on lung morphometry were analyzed by unpaired $t$ test. A probability level of $p<0.05$ was designated as indicating significance. Results are presented as mean \pm SEM.

\section{RESULTS}

Fetal physiologic data. Fetuses subjected to FGR had significantly lower $\mathrm{PaO}_{2}$ than controls $(13.7 \pm 0.6$ versus $20.0 \pm$ $1.0 \mathrm{~mm} \mathrm{Hg}$ ); similarly, arterial oxygen saturation was lower in FGR fetuses $(31.1 \pm 2.0$ versus $54.7 \pm 2.4 \%)$. FGR fetuses had significantly elevated $\mathrm{PaCO}_{2}$ compared with controls (53.9 \pm 0.7 versus $49.2 \pm 1.3 \mathrm{~mm} \mathrm{Hg}$ ), whereas arterial $\mathrm{pH}$ was not different (FGR, $7.33 \pm 0.01$ versus control, $7.35 \pm 0.01 ; p=$ $0.07)$. FGR fetuses had lower blood glucose concentrations than controls $(0.5 \pm 0.0$ versus $0.7 \pm 0.1 \mathrm{mM})$, whereas blood lactate concentrations were not different (both groups, $1.0 \pm$ $0.1 \mathrm{mM}$ ). Animals subjected to FGR were born at an earlier gestational age than controls $(142.5 \pm 0.1$ versus $147.0 \pm$ $1.1 \mathrm{~d} ; p<0.05$ ); the mean birth weight of the FGR animals $(2.66 \pm 0.14 \mathrm{~kg})$ was $41.3 \%$ less than that of controls $(4.53 \pm$ $0.32 \mathrm{~kg}, p<0.001)$.

Postnatal physiologic data. Between birth and $1 \mathrm{wk}$ of age, $\mathrm{PaO}_{2}$ was lower in FGR lambs than in controls $(68.8 \pm 4.6$ versus $88.8 \pm 7.4 \mathrm{~mm} \mathrm{Hg} ; p<0.05$ ), and $\mathrm{PaCO}_{2}$ was higher (44.7 \pm 1.3 versus $38.8 \pm 1.5 \mathrm{~mm} \mathrm{Hg} ; p<0.05$ ); arterial $\mathrm{pH}$ was not different. Between $1 \mathrm{wk}$ after birth and $18 \mathrm{mo}$, there were no significant differences in arterial gas tensions or $\mathrm{pH}$ between FGR and control animals. Similarly, at $2 \mathrm{y}$, there were no differences in $\mathrm{PaO}_{2}(\mathrm{FGR}, 108.1 \pm 1.8$ versus control, 111.0 $\pm 3.4 \mathrm{~mm} \mathrm{Hg}$ ), $\mathrm{PaCO}_{2}$ (FGR, $35.2 \pm 1.0$ versus control, $36.5 \pm$ $1.2 \mathrm{~mm} \mathrm{Hg}$ ), or arterial $\mathrm{pH}$ (FGR, $7.47 \pm 0.01$ versus control, $7.47 \pm 0.01)$. At autopsy, there was no difference in body weights between FGR $(61.2 \pm 1.9 \mathrm{~kg})$ and control $(63.6 \pm 3.9$ $\mathrm{kg}$ ) animals. Static lung compliance, measured from the pressure-volume curves, was not different between groups (Fig. 1). There was also no difference when values were adjusted for BW, lung weight, or calculated total lung volume; when adjusted for lung volume, lung compliance was $108 \pm 16 \mathrm{~mL}$ $\cdot \mathrm{cm} \mathrm{H} \mathrm{H}_{2} \mathrm{O}^{-1} \cdot \mathrm{L}^{-1}$ in FGR animals and $120 \pm 19 \mathrm{~mL} \cdot \mathrm{cm}$ $\mathrm{H}_{2} \mathrm{O}^{-1} \cdot \mathrm{L}^{-1}$ in controls.

Lung volumes and weights. In $\mathrm{FGR}$ animals, total lung volume was not different from that of controls (FGR, $1247 \pm$ 90 versus controls, $1183 \pm 102 \mathrm{~mL} ; p>0.05$ ); however, after adjustment for BW, the lung volume of FGR animals was greater than in controls (FGR, $21.8 \pm 1.1$ versus controls, 18.1 $\pm 0.7 \mathrm{~mL} / \mathrm{kg} ; p<0.01$ ). The wet and dry weights of the lungs of FGR animals were not significantly different from those of controls (Table 2). When adjusted for BW, wet and dry lung weights of FGR animals were not different from those of controls. Consequently, the pulmonary water content of FGR animals $(81.4 \pm 1.0 \%)$ was not different from that of controls $(80.8 \pm 0.5 \%, p>0.05)$. 


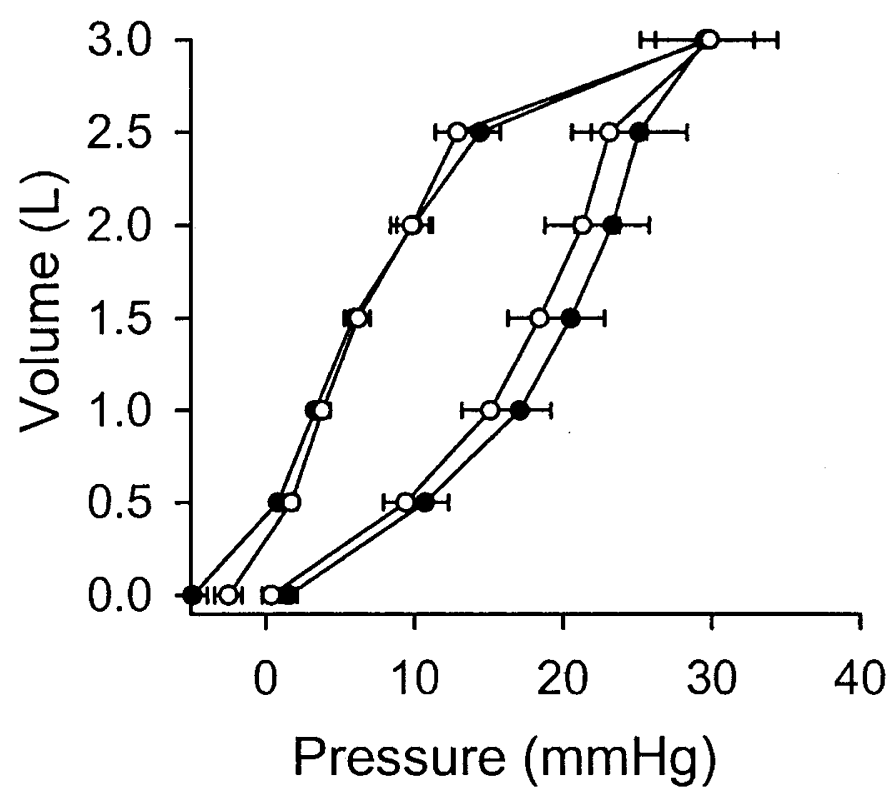

Figure 1. Pressure-volume relationships in the lungs of control ( $($ ) and FGR (๑) sheep during inflation and deflation with known volumes of air.

Table 2. Measurements made from the lungs of sheep at $2 y$ after birth

\begin{tabular}{lcc}
\hline & Control & FGR \\
\hline Wet lung weight $(\mathrm{g})$ & $619.0 \pm 51.8$ & $679.1 \pm 47.4$ \\
Wet lung weight $(\mathrm{g} / \mathrm{kg} \mathrm{BW})$ & $9.6 \pm 0.3$ & $11.1 \pm 0.7 \dagger$ \\
Dry lung weight $(\mathrm{g})$ & $119.1 \pm 11.3$ & $129.1 \pm 13.6$ \\
Dry lung weight $(\mathrm{g} / \mathrm{kg} \mathrm{BW})$ & $1.84 \pm 0.06$ & $2.10 \pm 0.20$ \\
Water content of lungs $(\%)$ & $80.8 \pm 0.5$ & $81.4 \pm 1.0$ \\
Lung DNA concentration $(\mathrm{mg} / \mathrm{g}$ lung) & $4.51 \pm 0.19$ & $4.49 \pm 0.17$ \\
Total lung DNA content $(\mathrm{g})$ & $2.74 \pm 0.18$ & $3.03 \pm 0.23$ \\
Total lung DNA content $(\mathrm{mg} / \mathrm{kg} \mathrm{BW})$ & $43.4 \pm 2.2$ & $49.4 \pm 3.1$ \\
Lung protein concentration $(\mathrm{mg} / \mathrm{g}$ lung) & $124.6 \pm 6.1$ & $128.3 \pm 3.4$ \\
Total lung protein content $(\mathrm{g})$ & $77.4 \pm 7.5$ & $86.9 \pm 6.1$ \\
Total lung protein content $(\mathrm{g} / \mathrm{kg} \mathrm{BW})$ & $1.20 \pm 0.07$ & $1.42 \pm 0.09 \dagger$ \\
DNA/protein ratio & $0.038 \pm 0.003$ & $0.035 \pm 0.002$ \\
\hline
\end{tabular}

$\dagger$ Indicates differences between groups $(p=0.07)$.

Pulmonary composition. Pulmonary DNA and protein concentrations (mg/g tissue) were not different between control and FGR sheep (Table 2). Total pulmonary DNA and protein contents were not different between groups; however, when values were related to $\mathrm{BW}$ they tended to be $14 \%(p=0.1)$ and $18 \%(p=0.07)$ higher, respectively, in FGR animals than in controls (Table 2). The ratio of DNA to protein concentrations was not different between groups. Similarly, the elastin concentration of lung tissue was not different between groups (control, $5.6 \pm 0.2$ versus $\mathrm{FGR}, 5.2 \pm 0.4 \mathrm{mg} / \mathrm{g}$ lung). The total pulmonary elastin content (control, $2.96 \pm 0.17$ versus FGR, $3.88 \pm 0.39 \mathrm{~g}$ ) and elastin content adjusted for BW (control, $50.9 \pm 2.8$ versus FGR, $64.5 \pm 5.8 \mathrm{mg} / \mathrm{kg}$ ) were also not different.

Lung morphometry. The Tw of FGR animals was $5.99 \pm$ $1.36 \mu \mathrm{m}$, which was $57 \%$ greater than in controls $(3.80 \pm 0.66$ $\mu \mathrm{m}, p<0.001$; Fig. $2 A$ ). The Lm was $11 \%$ greater in FGR animals than in controls $(102.8 \pm 3.8$ versus $92.3 \pm 2.7 \mu \mathrm{m}$, $p<0.001)$. Valv in FGR animals $(11.79 \pm 1.40 \mu \mathrm{L})$ was $47 \%$ greater than in controls $(8.02 \pm 1.03 \mu \mathrm{L}, p<0.001$; Fig. $2 B)$.
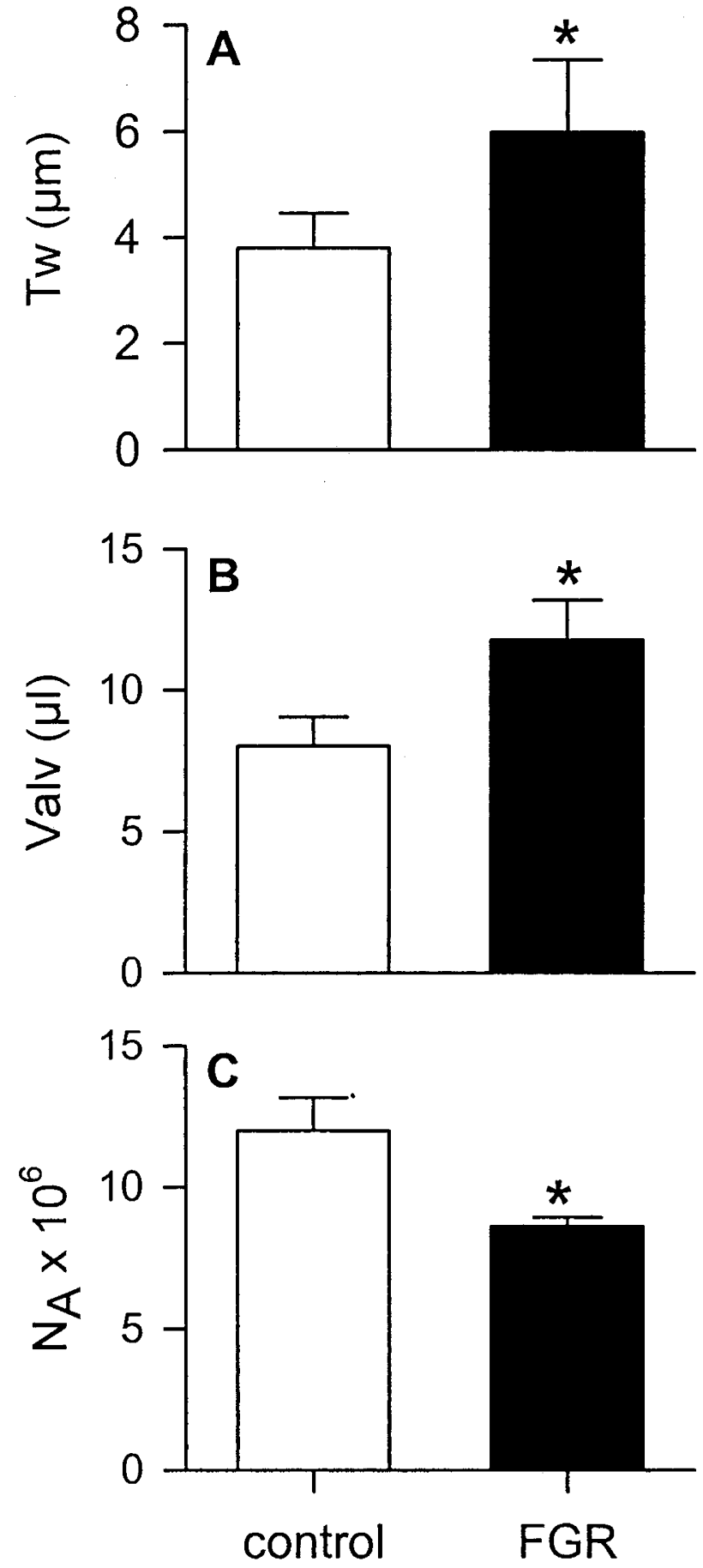

Figure 2. Effect of FGR on the Tw $(A)$, Valv $(B)$, and $\mathrm{N}_{\mathrm{A}}(C)$ in 2-y-old sheep. Asterisks denote significant differences $(p<0.05)$ between groups.

There were $28.1 \%$ fewer alveoli (Fig. $2 C$ ) in the lungs of the FGR animals $\left(8.62 \pm 0.32 \times 10^{6}\right)$ than in controls $(11.99 \pm$ $\left.1.16 \times 10^{6}, p<0.01\right)$. The $\mathrm{S}_{\mathrm{A}}$ of the lungs of FGR animals $\left(48.87 \pm 2.85 \mathrm{~m}^{2}\right)$ was not different from that of controls $\left(49.76 \pm 3.95 \mathrm{~m}^{2}\right)$, but was lower when adjusted for BW (Fig. $3 A$; FGR, $0.70 \pm 0.03$ versus control, $0.85 \pm 0.03 \mathrm{~m}^{2} / \mathrm{kg} ; p<$ $0.01)$. The airspace wall surface area per unit volume (i.e. $\mathrm{S}_{\mathrm{V}}$; Fig. $3 B)$ of the FGR animals $\left(1.95 \pm 0.03 \mathrm{~mm}^{2} / \mathrm{mm}^{3}\right)$ was $10 \%$ less than in controls $\left(2.17 \pm 0.03 \mathrm{~mm}^{2} / \mathrm{mm}^{3}, p<0.01\right)$. The 

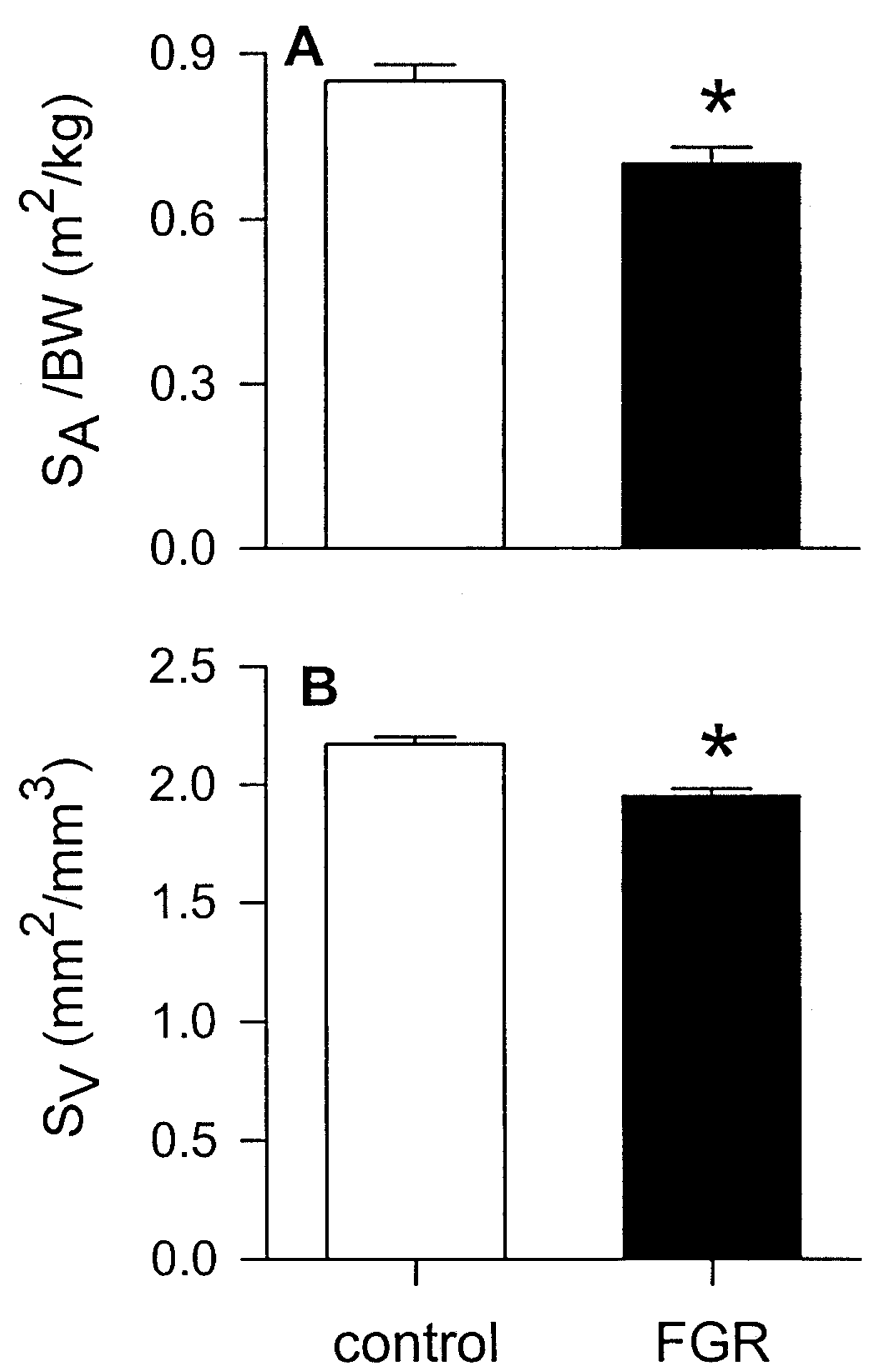

Figure 3. Effect of FGR on $\mathrm{S}_{\mathrm{A}} / \mathrm{BW}(A)$ and $\mathrm{S}_{\mathrm{V}}(B)$ of 2-y-old sheep. Asterisks show significant differences $(p<0.05)$ between groups.

volume density of airspace in the lungs $\left(\mathrm{V}_{\mathrm{A}}\right)$ was not significantly different between groups (FGR, $82.8 \pm 1.1 \%$ versus controls, $84.7 \pm 1.2 \%$ ).

TEM revealed differences in the blood-air barrier of FGR and control sheep (Fig. 4). The $\mathrm{T}_{\mathrm{hBAB}}$ of FGR sheep was $43 \%$ greater than that of controls (FGR, $0.40 \pm 0.04$ versus controls, $0.28 \pm 0.02 \mu \mathrm{m} ; p<0.001)$. The harmonic mean thicknesses of the epithelial and endothelial components of the blood-air barrier of FGR sheep $(0.16 \pm 0.02 \mu \mathrm{m}$ and $0.14 \pm 0.02 \mu \mathrm{m}$, respectively) were not different from values in controls $(0.12 \pm$ $0.01 \mu \mathrm{m}$ and $0.12 \pm 0.02 \mu \mathrm{m}$, respectively; both $p>0.05$ ). The basement membrane of the blood-air barrier of the FGR sheep $(0.10 \pm 0.01 \mu \mathrm{m})$ was $82 \%$ thicker than in controls $(0.06$ $\pm 0.01 \mu \mathrm{m}, p<0.005)$. This basement membrane was of uneven thickness in contrast to that in controls (Fig. 5).

TEM also showed that FGR resulted in altered structural features of the alveolar septa. Changes included a thickening of the basement membranes that separate fibroblasts from the epithelial and endothelial cells of the blood-air barriers as a result of an accumulation of ECM (Fig. 6). The cell junctions between septal fibroblasts of FGR sheep appeared to be not as

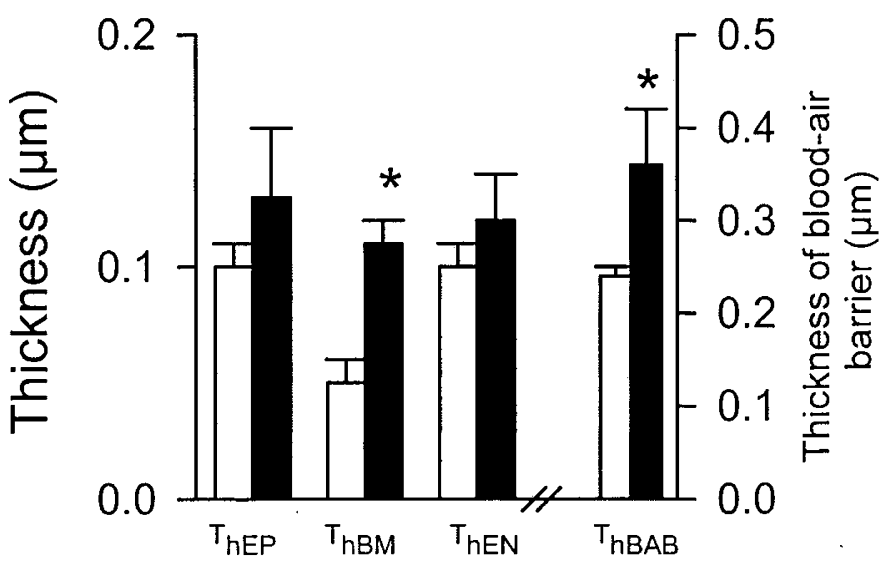

Figure 4. Effect of FGR on the $\mathrm{T}_{\mathrm{hBAB}}$ and its components. The $\mathrm{T}_{\mathrm{hBAB}}$ of FGR sheep was significantly greater $(p<0.05)$ than that of control sheep. The mean thicknesses of the epithelium $\left(T_{h E P}\right)$ and endothelium $\left(T_{h E N}\right)$ were not significantly different from those of controls. The harmonic mean thickness of the basement membrane $\left(T_{h B M}\right)$ of FGR sheep was greater $(p<0.05)$ than that of controls.
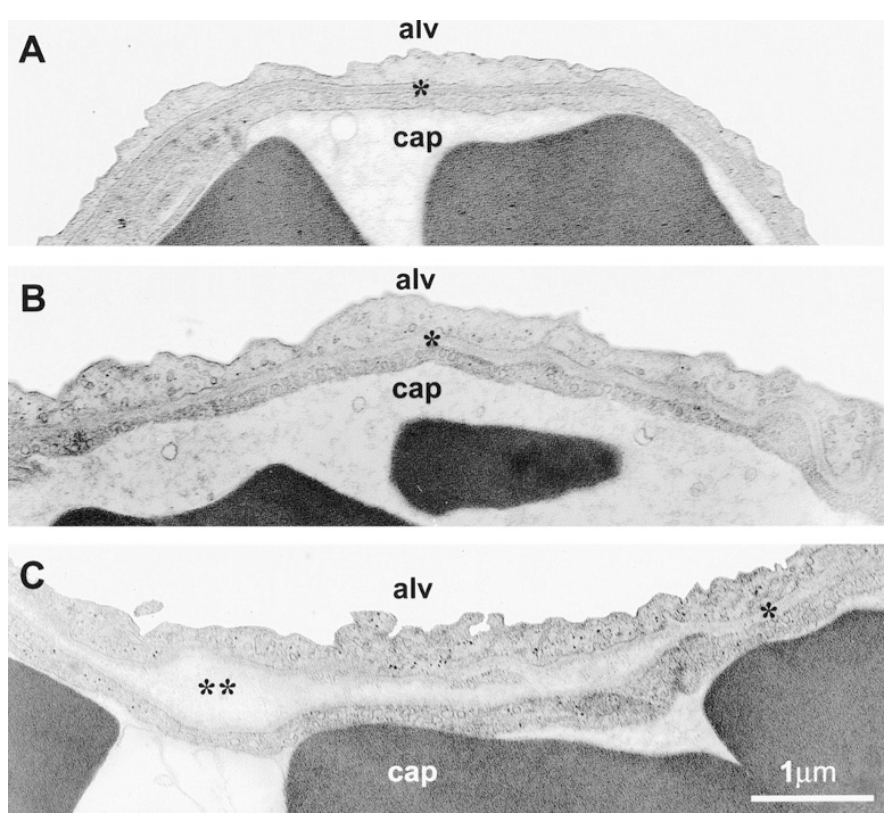

Figure 5. Electron micrographs of blood-air barriers of alveolar walls of 2-y-old control $(A)$ and FGR sheep $(B, C)$. In controls $(A)$, the basement membrane of the blood-air barrier (asterisk) is of even thickness with a continuous lamina densa. In FGR sheep, the basement membrane of some of the blood-air barriers $(B)$ was of even thickness (asterisk), whereas others (as shown in $C$ ) were of uneven thickness because of the accumulation of ECM between the epithelial cell and the lamina densa (double asterisk). (alv, alveolar side of blood-air barrier lined by type I alveolar epithelial cells; cap, capillary side of the blood-air barrier lined by endothelial cells) Bar $=1.0 \mu \mathrm{m}$ (applies to $A-C$ ).

tight as in controls, and thick layers of ECM were observed between adjacent fibroblasts in FGR sheep (Fig. 6, $A$ and $B$ ). The mitochondria and RER of the fibroblasts tended to be larger compared with those of controls (Fig. 6, $A$ and $B$ ). In septa of control sheep, mast cells occurred infrequently, usually as single cells interspersed with fibroblasts. In septa of FGR sheep, numerous mast cells occurred grouped together in the corners of the alveoli; three or more cells were often 


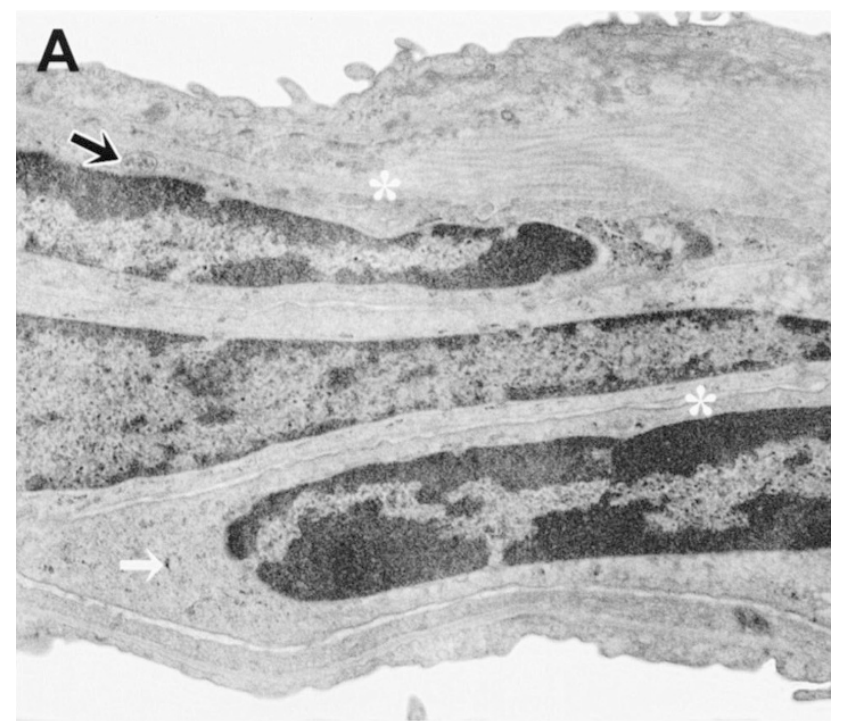

grouped together (Fig. 6, $B$ and $C$ ). In contrast to the fibroblasts, the RER and mitochondria of alveolar type II cells were not affected by FGR (Fig. 7).

We used scanning electron microscopy to observe the surface morphology of the alveoli in control and FGR sheep $(n=$ 4 each group). Although we could not quantify them, it is apparent that more fenestrations (pores of Kohn) were present in the alveolar walls of the lungs of each of the four FGR sheep than in the four control sheep (Fig. 8).

\section{DISCUSSION}

Structural changes observed in mature FGR sheep were similar both qualitatively and quantitatively to those observed previously in 8-wk-old FGR lambs (12); in addition we observed fenestrations in alveolar walls that were not present at 8 wk. Most of these changes were not seen in the near-term fetus (12) but developed after birth. It is apparent that some alterations, such as a lower $\mathrm{N}_{\mathrm{A}}$ and an increase in $\mathrm{Tw}$, became more pronounced as the lungs develop after birth. The structural changes seen in the lungs of FGR animals at 8 wk after birth
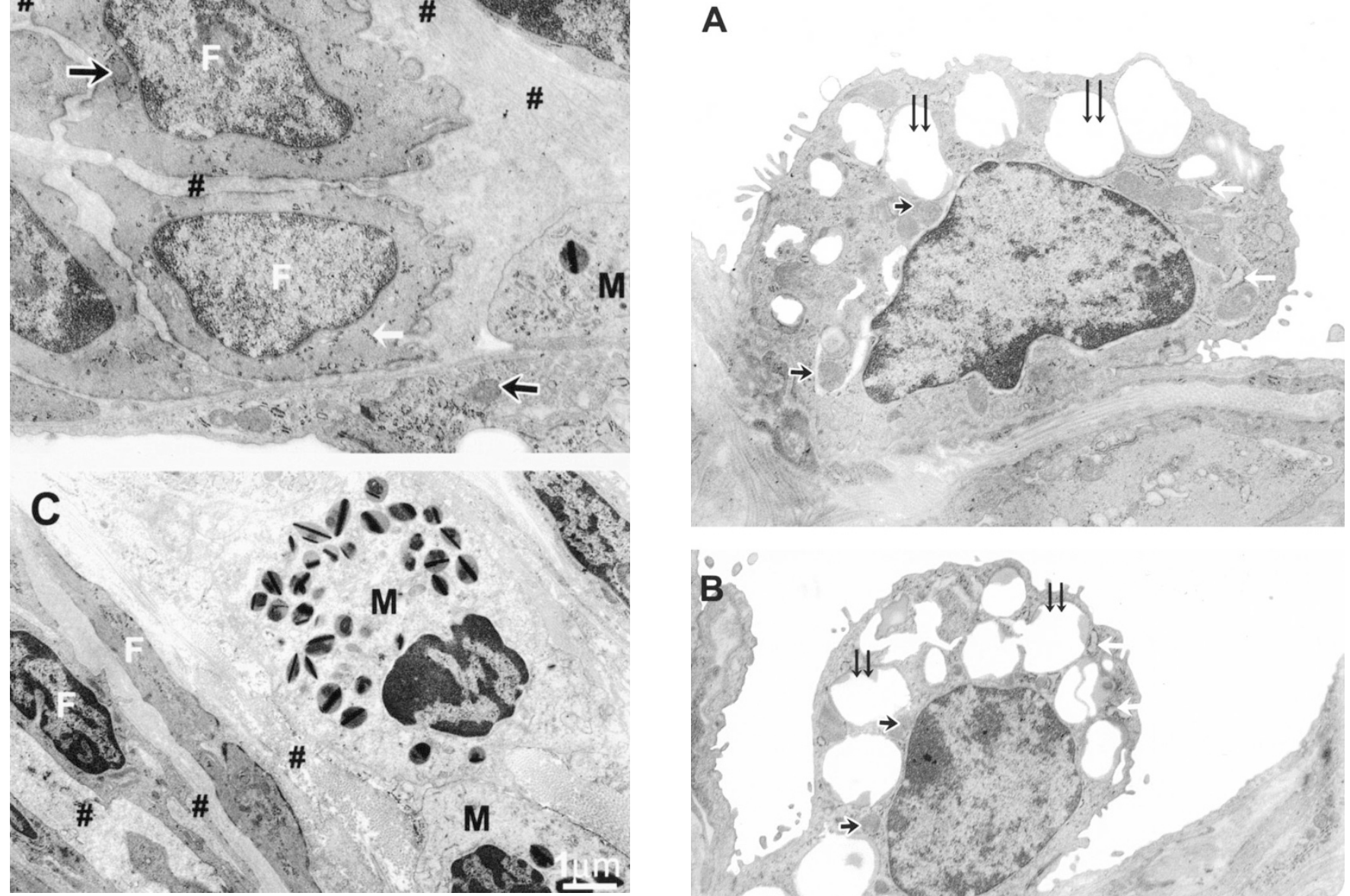

Figure 6. Electron micrographs of the alveolar walls of control $(A)$ and FGR ( $B$ and $C$ ) sheep $2 \mathrm{y}$ after birth. The basement membranes of adjacent interstitial cells in the alveolar walls of the control lung $(A)$ are thin (asterisks), resulting in the cells being in close contact. In the FGR sheep $(B$ and $C)$ spaces between adjacent interstitial cells are prominent and filled with ECM (\#). The fibroblasts $(F)$ and mast cells $(M)$ are often separated by thick layers of ECM. Mitochondria (black arrows) are larger and the rough endoplasmic reticulum (white arrows) more prominent than in interstitial cells of the control lung. Bar $=1.0 \mu \mathrm{m}$ (applies to

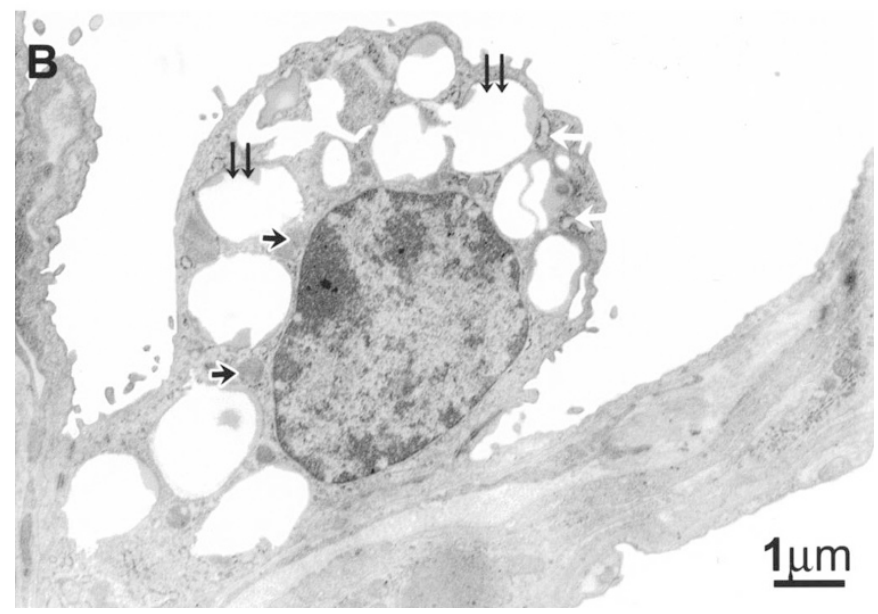

Figure 7. Electron micrographs of alveolar type II cells of 2-y-old control $(A)$ and FGR $(B)$ sheep. The mitochondria (single black arrows), RER (white arrows), and lamellar bodies (double black arrows) in these cells were similar in both groups of sheep. Bar $=1.0 \mu \mathrm{m}$ (applies to $A$ and $B$ ). 

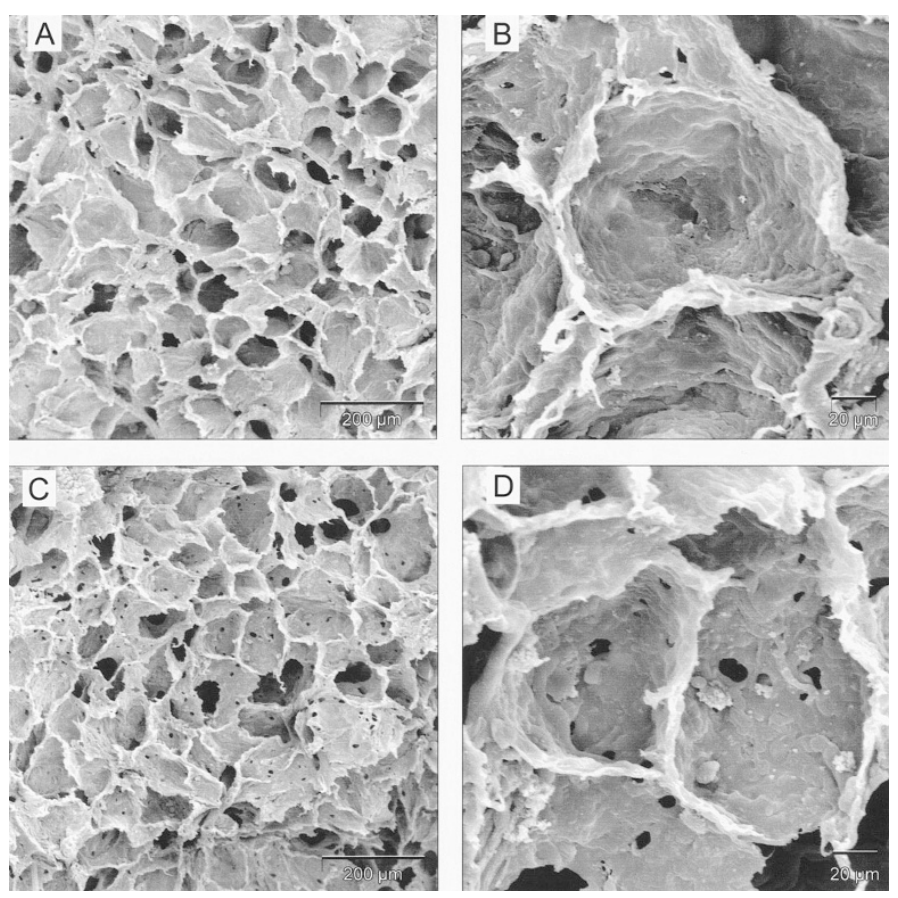

Figure 8. Scanning electron micrographs of the alveolar surface of lung tissue of 2-y-old control $(A$ and $B$ ) and FGR sheep $(C$ and $D$ ). The alveolar fenestrations (pores of Kohn) in the lungs of FGR sheep were more numerous than in control sheep.

(12) and at maturity were likely a result of prenatal growth restriction as there was no evidence that the growth of the FGR lambs after birth was restricted. Although FGR lambs remained small at $8 \mathrm{wk}$ after birth (12), by approximately $2.3 \mathrm{y}$ there was no difference in the body or lung weights of the two groups.

In interpreting the effects of chronic placental insufficiency on fetal lung development, it is necessary to consider the stages of lung development that coincide with the prenatal insult, as well as the duration and severity of the insult. In our study, the late gestational UPE coincided with the saccular and alveolar stages of lung development (9); hence we have focused on the gas-exchanging components of the lungs.

Thickness of alveolar walls. In control animals, thinning of the alveolar septa was completed by $140 \mathrm{~d} \mathrm{GA}$, and no further thinning occurred after birth (12). Although there was no difference in the thickness of the alveolar septa between control and FGR fetuses near term (12), the alveolar septa of FGR animals were markedly thicker than those of controls at $8 \mathrm{wk}$ (12) and $2 \mathrm{y}$ after birth. This suggests that the in utero development of alveolar septa was not affected by placental insufficiency and FGR, but that thickening of the alveolar walls occurred after $140 \mathrm{~d} \mathrm{GA}$, during the late alveolar and postalveolar phases of lung development. Inasmuch as the lung wet weight-to-dry weight ratios of the adult control and FGR sheep were not different, it is unlikely that edema contributed to thickening of the alveolar walls. The pulmonary DNA and protein data suggest that the cell numbers and cell size in the alveolar walls were similar to those in controls. Thus it is likely that the accumulation of ECM was the major cause of alveolar wall thickening at $8 \mathrm{wk}(12)$ and $2 \mathrm{y}$; this was confirmed by
TEM, which clearly showed thick layers of ECM and thickened basement membranes. Our data show that pulmonary elastin content of 2-y-old animals was not affected by FGR, and therefore did not contribute to the increase in ECM and thicker alveolar walls of the 2-y-old FGR lambs. It therefore appears that glycoprotein synthesis in the RER of the septal fibroblasts of FGR sheep may have been increased.

Septal thickening after the period that is normally associated with thinning of the alveolar septa suggests that the consequences of FGR may not necessarily be apparent during, or at the end of, a particular phase of lung development but may develop later in life. The observation that the septal thickness of adult FGR sheep resembled that of 8-wk-old FGR lambs (12) suggests that the thickening of the alveolar septa in FGR lambs is irreversible. It also suggests that factors that induce the thickening of the alveolar septa of FGR animals are not active after $8 \mathrm{wk}$. It is therefore likely that the rate of synthesis and degradation of ECM components after 8 wk was balanced so as to maintain the increased thickness of the alveolar walls of FGR animals.

The reason for the greater accumulation of ECM in the alveolar walls and in the basement membranes of the blood-air barrier in FGR animals is unknown. It is, however, interesting that fibroblasts in the alveolar walls of FGR sheep had enlarged mitochondria and a more prominent RER, indicative of increased activity of these organelles (30). It has been shown in rats that after a single episode of neonatal hypoxia, pulmonary fibroblasts and endothelial cells show an unusual dilatation of the RER that persisted for 3 mo (31), indicating that hypoxia can exert a persistent alteration in the metabolic processes in these cells. Other studies have shown that hypoxia stimulates ECM production by fibroblasts $(32,33)$. As the $\mathrm{PaO}_{2}$ of the FGR animals in both our present and previous studies (11) was lower during the early postnatal period than in controls, it is plausible that the accumulation of ECM in the alveolar walls of the lungs of the FGR sheep was induced by early postnatal hypoxia. The absence of a difference in $\mathrm{PaO}_{2}$ between the groups after the neonatal period may explain why there was no further thickening of the alveolar walls after $8 \mathrm{wk}$. An alternative explanation for differences in ECM deposition between groups is that owing to the reduced number of larger alveoli in FGR animals, the breathing-related distribution of alveolar wall tension may have differed from that in controls; increased deposition of ECM in FGR animals may have been an adaptive response to resist higher levels of alveolar wall tension during normal tidal breathing.

The blood-air barrier. The blood-air barrier of the adult FGR sheep, like those of the FGR fetuses and 8-wk-old lambs (12), was markedly thicker than that of controls. A comparison of data from our previous study (12) with the findings of the present study shows that the thickness of the blood-air barrier of the FGR and control animals remains constant after birth, and that the difference in thickness is maintained for $2 \mathrm{y}$. Our morphometric analysis shows that the thicker blood-air barrier of the lungs of FGR sheep was the result of a thicker basement membrane, suggesting that once the basement membrane is laid down, its thickness remains unchanged. The reason for this is unknown, but it is clear that the increased thickness of the 
basement membrane occurs before birth. The thicker basement membrane was likely maintained by the synthesis and deposition of basement membrane during lung development exceeding the rate of degradation.

It is known that entactin, which is produced by the alveolar epithelial cells, is an integral basement membrane component that binds laminin and type IV collagen (34). Entactin, laminin-1, and type IV collagen are expressed in developing lung during late gestation and early neonatal life (34). Laminin and entactin are required for the synthesis of a continuous lamina densa in the basement membrane (35). In our study we found a continuous lamina densa in the basement membrane of the blood-air barriers of both groups of adult sheep. This implies that the synthesis and release of these proteins by the fibroblasts and type II cells (36) were not affected by the hypoxia or lack of nutrients associated with FGR during the saccular and early alveolar phase of lung development.

Alveolar number and dimensions. We recently showed that alveolarization continues to occur after birth in the sheep and that the alveolar number per respiratory unit of 8-wk-old FGR sheep is less than that of controls (12). Two years after birth, the $\mathrm{N}_{\mathrm{A}}$ of sheep subjected to FGR was still lower than in controls. Because the difference in $\mathrm{N}_{\mathrm{A}}$ of the FGR and control sheep remained essentially unaltered between postnatal wk 8 (12) and $2 \mathrm{y}$ of age, it is unlikely that there will be catch up of the alveolar numbers as the animals age because alveolarization would have come to an end.

We recently showed that the induction of UPE had no influence on alveolar size in the fetus and thus on the prenatal formation of secondary septa (12). The increase in alveolar size between $140 \mathrm{~d}$ GA and $8 \mathrm{wk}$ after birth, which was seen in both groups (Table 3), was caused by enlargement of the existing airspaces, as described previously in normal animals (12). An increase in alveolar volume, as a result of progressive destruction of the alveolar walls, is associated with the development of emphysema. Various definitions of pulmonary emphysema have been proposed, all of which include reference to the abnormal enlargement of airspaces distal to the terminal bronchiole $(37,38)$. The greater Lm and Valv in adult FGR sheep, compared with controls, is an indication of abnormal enlargement of the airspaces. This is, however, not necessarily indicative of emphysema because there are no baseline data for $\mathrm{Lm}$ and Valv for emphysema. On the other hand, $\mathrm{S}_{\mathrm{V}}$ is an objective quantitative method for the identification of microscopic emphysema.

The $S_{V}$ of human lungs decreases linearly with advancing age after lung development stops (39). If the reduction in $S_{V}$ within an age group is greater than $5 \%$ it is regarded as a sign of microscopic emphysema (39). In the present study, $\mathrm{S}_{\mathrm{V}}$ in FGR sheep was $10.1 \%$ lower than in controls, implying that their lungs have signs of microscopic emphysema. In addition, scanning microscopy showed a greater number of fenestrations in the alveolar walls in the 2-y-old FGR sheep than in controls. According to some studies these fenestrations (pores of Kohn) are related to the onset and presence of emphysema (40).

Effects of postnatal age on the lungs of normal and FGR sheep. In Table 3 we use data from our previous study (12) and the present study to document age-related changes in the lungs of normal and FGR sheep. It is known that thinning of the septal walls occurs as the lung matures (41). In this study we showed that septal thinning was completed before birth as no further thinning occurred after birth. However, thinning of the blood-air barrier does occur after $140 \mathrm{~d}$ of gestation. Between $8 \mathrm{wk}$ and $2 \mathrm{y}$ after birth the thickness of the blood-air barrier of the control animals remained unchanged. In contrast, in FGR animals, the septal walls increased markedly in thickness after birth and, as in control animals, this thickness was maintained to maturity. Although the blood-air barrier of the FGR animals also became thinner after birth, it remained thicker than in controls; such a thickening has been associated with aging of the lungs (42).

Breaks in the continuity of the alveolar septum accompanied by epithelial discontinuity are recognized as pores of Kohn (43). These pores were not observed in the lungs of 140-d-old fetuses and 8-wk-old lambs (12), but at $2 \mathrm{y}$ of age they were present in both the control and FGR sheep. However, more pores were apparent in the alveoli of the mature FGR sheep than in control sheep. The increase in the number and size of the pores of Kohn is recognized as an early sign of alveolar senescence (44) and emphysema (45). Thus, the lungs of the FGR sheep were apparently aging more rapidly than those of controls.

Although mast cells were rarely seen in the alveolar septa of control sheep, they were often present in FGR sheep at 2 y. In the controls, these cells occurred singly whereas in FGR sheep they were usually grouped together in clusters of three or more.

Table 3. Comparison of pulmonary morphometric data from control and FGR sheep as near-term fetuses (140 d of gestation), at 8 wk after birth, and at $2 y$ after birth

\begin{tabular}{|c|c|c|c|c|c|c|}
\hline & \multicolumn{2}{|c|}{$140 \mathrm{~d}$ of gestation } & \multicolumn{2}{|c|}{8 wk after birth } & \multicolumn{2}{|c|}{$2 \mathrm{y}$ after birth } \\
\hline & Control & FGR & Control & FGR & Control & FGR \\
\hline Tw & $3.49 \pm 0.04$ & $3.29 \pm 0.14$ & $3.74 \pm 0.16$ & $6.49 \pm 0.01 *$ & $3.80 \pm 0.66$ & $5.99 \pm 1.36^{*}$ \\
\hline $\mathrm{T}_{\mathrm{hBAB}}$ & $0.34 \pm 0.01$ & $0.50 \pm 0.02 *$ & $0.24 \pm 0.01$ & $0.36 \pm 0.06^{*}$ & $0.28 \pm 0.02$ & $0.40 \pm 0.04 *$ \\
\hline $\mathrm{T}_{\mathrm{hEP}}$ & $0.14 \pm 0.02$ & $0.16 \pm 0.02$ & $0.10 \pm 0.007$ & $0.15 \pm 0.01$ & $0.12 \pm 0.01$ & $0.16 \pm 0.02$ \\
\hline $\mathrm{T}_{\mathrm{hEN}}$ & $0.14 \pm 0.02$ & $0.17 \pm 0.01 *$ & $0.10 \pm 0.008$ & $0.12 \pm 0.02$ & $0.12 \pm 0.01$ & $0.14 \pm 0.02$ \\
\hline
\end{tabular}

All dimensions are in micrometers. Data from 140-d-old fetuses and 8-wk-old lambs are taken from Maritz et al. (12). * Significant difference between control and FGR $(p<0.05)$. $\mathrm{T}_{\mathrm{hEP}}$, thickness of the epithelial cell; $\mathrm{T}_{\mathrm{hEN}}$, thickness of the endothelial cell; $\mathrm{T}_{\mathrm{hBM}}$, thickness of basement membrane. 
The reason for this is not clear; however, it has been shown that the mast cell population in rat lungs increases with age (46). Taken together, the data from our study suggest that the lungs of our FGR sheep were aging faster than those of the control sheep.

\section{CONCLUSIONS}

We conclude that changes in lung structure induced by FGR during the saccular and alveolar phases of fetal lung development were present in adult sheep and were of similar magnitude to those previously seen at $8 \mathrm{wk}$ of age. This indicates that the changes induced by hypoxemia or nutrient restriction during early stages of lung development were permanent. In the lungs of mature FGR sheep, the presence of a smaller number of larger alveoli, together with evidence of increased numbers of mast cells and alveolar fenestrations, is suggestive of premature lung aging. The long-term functional consequences of emphysematous alterations in lung structure are presently unknown, but they could affect later respiratory health and the rate of lung aging.

Acknowledgments. The authors thank Alex Satragno for surgical and technical assistance, Kerryn Westcott for performing the assays, Sharon Flecknoe for preparing tissue for electron microscopy and photography, Belinda Joyce for performing the elastin analysis, and Dr. Stuart Hooper for his interest in this study.

\section{REFERENCES}

1. Ounsted M, Moar V, Scott WA 1981 Perinatal morbidity and mortality in small-fordates babies: the relative importance of some maternal factors. Early Hum Dev 5:367-375

2. Kramer MS, Olivier M, McLean FH, Willis DM, Usher RH 1990 Impact of intrauterine growth retardation and body proportionality on fetal and neonatal outcome. Pediatrics 86:707-713

3. Tyson JE, Kennedy K, Broyles S, Rosenfeld CR 1995 The small for gestational age infant: accelerated or delayed pulmonary maturation? Increased or decreased survival? Pediatrics 95:534-538

4. Minior VK, Divon MY 1998 Fetal growth restriction at term: myth or reality? Obstet Gynecol 92:57-60

5. Rona RJ, Gulliford MC, Chinn S 1993 Effects of prematurity and intrauterine growth on respiratory health and lung function in childhood. BMJ 306:817-820

6. Nikolajev K, Heinonen K, Hakulinen A, Lansimies E 1998 Effects of intrauterine growth retardation and prematurity on spirometric flow values and lung volumes at school age in twin pairs. Pediatr Pulmonol 25:367-370

7. Barker DJP, Godfrey KM, Fall C, Osmond C, Winter PD, Shaheen SO 1991 Relation of birth weight and childhood respiratory infection to adult lung function and death from chronic obstructive airways disease. BMJ 303:671-675

8. Stein CE, Kumaran K, Fall CH, Shaheen SO, Osmond C, Barker DJ 1997 Relation of fetal growth to adult lung function in south India. Thorax 52:895-899

9. Alcorn DG, Adamson TM, Maloney JE, Robinson PM 1981 A morphologic and morphometric analysis of fetal lung development in the sheep. Anat Rec 201:655667

10. Burri PH 1986 Development and growth of the human lung. In: Fishman AP, Cherniack NS, Widdicombe JG, Geiger SR (eds) Handbook of Physiology. American Physiological Society, Bethesda, pp 1-46

11. Joyce BJ, Louey S, Davey MG, Cock ML, Hooper SB, Harding R 2001 Compromised respiratory function in postnatal lambs after placental insufficiency and intrauterine growth restriction. Pediatr Res 50:641-649

12. Maritz GS, Cock ML, Louey S, Joyce BJ, Albuquerque CA, Harding R 2001 Effect of fetal growth restriction on lung development before and after birth: a morphometric analysis. Pediatr Pulmonol 32:201-210

13. Soothill PW, Nicolaides KH, Campbell S 1987 Prenatal asphyxia, hyper-lactinaemia, hypoglycaemia and erythroblastosis in growth retarded fetuses. BMJ 294:1051-1053
14. Nicolaides KH, Economides DL, Soothill PW 1989 Blood gases, pH, and lactate in appropriate- and small-for-gestational-age fetuses. Am J Obstet Gynecol 161:9961001

15. Trudinger BJ, Stevens D, Connelly A, Hales JR, Alexander G, Bradley A 1987 Umbilical artery flow velocity waveforms and placental resistance: the effects of embolization of the umbilical circulation. Am J Obstet Gynecol 157:1443-1448

16. Gagnon R, Challis J, Johnston L, Fraher L 1994 Fetal endocrine responses to chronic placental embolization in the late-gestation ovine fetus. Am J Obstet Gynecol 170:929-938

17. Cock ML, Harding R 1997 Renal and amniotic fluid responses to umbilicoplacental embolization for 20 days in fetal sheep. Am J Physiol 237:R1094-R1102

18. Louey S, Cock ML, Stevenson KM, Harding R 2000 Placental insufficiency and fetal growth restriction lead to postnatal hypotension and altered postnatal growth in sheep. Pediatr Res 48:808-814

19. Grassino AE, Roussos C 1997 Static properties of the lung and chest wall. In: Crystal JB, West JB, Weibel ER, Barnes PJ (eds) The Lung. Lippincott-Raven, Philadelphia, pp 1187-1201

20. Joyce BJ, Wallace MJ, Pierce RA, Harding R, Hooper SB 2003 Sustained changes in lung expansion alter tropoelastin mRNA levels and elastin content in fetal sheep lung. Am J Physiol 284:L643-L649

21. Scherle W 1970 A simple method for volumetry of organs in quantitative stereology. Mikroscopie 26:57-60

22. Van der Horst G, Kitchin RM, Curry PT, Atherton RW 1989 Use of membrane filters and osmium tetroxide etching in the preparation of sperm for scanning electron microscopy. J Electron Microsc Tech 12:65-70

23. Blanco LN, Massaro GD, Massaro D 1989 Alveolar dimensions and number: developmental and hormonal regulation. Am J Physiol 257:L240-L247

24. Boros V, Burghardt JS, Morgan CJ, Olson DM 1997 Leukotrienes are indicated as mediators of hypoxia-inhibited alveolarization in newborn rats. Am J Physiol 272:L433-L441

25. Gillooly M, Lamb D, Farrow AS 1991 New automated technique for the assessing emphysema on histological sections. J Clin Pathol 44:1007-1011

26. Butler C 1976 Lung surface area in various morphologic forms of human emphysema. Am Rev Respir Dis 114:347-352

27. Baddeley AJ, Gundersen HJ, Cruz-Orive LM 1986 Estimation of surface area from vertical sections. J Microsc 142:256-276

28. Weibel ER 1963 Morphometry of the Human Lung. Springer-Verlag, Berlin

29. Weibel ER, Knight BW 1964 A morphometric study of the thickness of the air-blood barrier. J Cell Biol 67:367-384

30. Widnell CC, Phenninger KH 1990 Essential Cell Biology. Williams \& Wilkins, Baltimore, pp 159-168

31. Zhang HF, Ong WY, Leong SK 1997 Ultrastructural changes in cerebral cortical blood vessels of immature and adult rats after a single episode of neonatal hypoxia. J Hirnforsch 38:81-97

32. Saed GM, Zhang W, Diamond MP 1998 Effects of hypoxia on stimulatory effects of TGF-beta 1 on MMP-2 and MMP-9 activities in mouse fibroblasts. J Soc Gynecol Invest 7:348-354

33. Orphanides C, Fine LG, Norman JT 1997 Hypoxia stimulates proximal tubular cell matrix production via TGF-beta 1-independent mechanism. Kidney Int 52:637-647

34. Senior RM, Griffin GL, Mudd MS, Moxley MA, Longmore WJ, Pierce RA 1996 Entactin expression by rat alveolar epithelial cells. Am J Respir Cell Mol Biol $14: 239-247$

35. Furuyama A, Mochitate K 2000 Assembly of the exogenous extracellular matrix during basement membrane formation by alveolar epithelial cells in vitro. J Cell Sci 113:859-868

36. Furuyama A, Kimata K, Mochitate K 1997 Assembly of basement membrane in vitro by cooperation between alveolar epithelial cells and pulmonary fibroblasts. Cell Struct Funct 22:603-614

37. Snider GL, Kleinerman J, Thurlbeck WM 1985 The definition of emphysema. Report of the National Heart, Lung and Blood Institute; Division of Lung Diseases Workshop. Am Rev Respir Dis 132:182-185

38. American Thoracic Society 1962 Statement on definitions and classification of emphysema. Am Rev Respir Dis 85:762-768

39. Gillooly M, Lamb D 1993 Microscopic emphysema in relation to age and smoking habit. Thorax 48:491-495

40. Cosio MG, Shiner RJ, Saetta M, Wang NS, King M, Ghezzo H, Angus E 1986 Alveolar fenestrae in smokers: relationship with light microscopic and functional abnormalities. Am Rev Respir Dis 133:126-131

41. Mansell AL, Collins MH, Johnson EJ, Gil J 1995 Postnatal growth of lung parenchyma in the piglet: morphometry correlated with mechanics. Anat Rec 241:99-104

42. Ustiuzhaninova NV, Shishkin GS 2002 Age changes in interalveolar septa and their relationship to a decrease in gas exchange. Morfologiia 121:84-88

43. Takaro T, Parra SC, Peduzzi PN 1985 Anatomical relationships between type II pneumonocytes and alveolar septal gas in the human lung. Anat Rec 213:540-550

44. Gillett NA, Gerlach RF, Muggenburg BA, Harkema JR, Griffith WC, Mauderly JL 1989 Relationship between collateral flow resistance and alveolar pores in the aging beagle dog. Exp Lung Res 15:709-719

45. Linhartova A 1986 Lesions in resected lung parenchyma with regard to possible initial phase of pulmonary emphysema. An ultrastructural study. Pathol Res Pract $181: 71-76$

46. Wilkes LK, McMenamin C, Holt PG 1992 Postnatal maturation of mast cell subpopulations in the rat respiratory tract. Immunology 75:535-541 